\title{
Comparative evaluation of ventilator-associated pneumonia in critically ill COVID-19 and patients infected with other corona viruses: a systematic review and meta-analysis
}

\author{
Shikha Jain ${ }^{1}$, Puneet Khanna², Soumya Sarkar² \\ ${ }^{1}$ Department of Anaesthesiology and Critical Care, All India Institute of Medical Sciences (AIIMS), Bhopal, Madhya \\ Pradesh; ${ }^{2}$ Department of Anaesthesiology, Pain Medicine and Critical care, All India Institute of Medical Sciences \\ (AIIMS), New Delhi, India
}

\begin{abstract}
The Coronavirus disease 19 (COVID-19) pandemic is associated with an unprecedented requirement for intensive care unit (ICU) admission, invasive mechanical ventilation, and thereby significantly increasing the risk of secondary nosocomial pneumonia, ventilator-associated pneumonia (VAP). Our study aims to identify the overall incidence of VAP, common organisms associated with it, and outcome in COVID-19 patients in comparison to the non-SARS-CoV-2 infected critically ill ventilated COVID-19 patients. A comprehensive screening was conducted using major
\end{abstract}

Correspondence: Dr. Soumya Sarkar, Department of Anaesthesia, Pain Medicine and Critical care, All India Institute of Medical Sciences (AIIMS)Ansari Nagar, New Delhi 110029, India.

E-mail: drsoumyasarkar@yahoo.co.in

Key words: COVID-19; severe acute respiratory syndrome coronavirus-2; SARS-CoV-2; ventilator-associated pneumonia; VAP.

Contributions: SJ, SS, search strategy, study selection, data extraction, manuscript drafting; PK, conceptualization, study selection, data extraction. All the authors have read and approved the final version of the manuscript and agreed to be accountable for all aspects of the work.

Conflict of interest: The authors declare that they have no competing interests, and all authors confirm accuracy.

Ethics approval and consent to participate: Not applicable.

Availability of data and material: Available with the corresponding author, can reproduce on appropriate request.

Funding: This research did not receive any specific grant from funding agencies in the public, commercial, or not-for-profit sectors.

Received for publication: 15 September 2020.

Accepted for publication: 12 August 2021.

${ }^{\circ}$ Copyright: the Author(s), 2021

Licensee PAGEPress, Italy

Monaldi Archives for Chest Disease 2022; 92:1610

doi: 10.4081/monaldi.2021.1610

This article is distributed under the terms of the Creative Commons Attribution Noncommercial License (by-nc 4.0) which permits any noncommercial use, distribution, and reproduction in any medium, provided the original author(s) and source are credited. electronic databases), from January $1^{\text {st }} 2020$ to May $31^{\text {st }} 2021$, as per the PRISMA statement. In our rapid review, we included a total of 34 studies (involving 8901 cases. Overall VAP was reported in $48.15 \%$ (95\% CI 42.3\%-54\%) mechanically ventilated COVID-19 patients and the mortality rate was $51.4 \%(95 \% \mathrm{CI}$ $42.5 \%-60 \%$ ). COVID-19 patients had increased risk of VAP and mortality in comparison to other non-SARS-CoV-2 viral pneumonia $\left(\mathrm{OR}=2.33 ; 95 \% \mathrm{CI} 1.75-3.11 ; \mathrm{I}^{2}=15 \%\right.$, and $\mathrm{OR}=1.46 ; 95 \% \mathrm{CI}$ $1.15-1.86 ; \mathrm{I}^{2}=0 \%$ respectively). Critically ill COVID-19 patients are prone to develop VAP, which worsens the outcome.

\section{Introduction}

The coronavirus disease 19 (COVID-19) pandemic, caused by severe acute respiratory syndrome coronavirus 2 (SARS-CoV-2) is a global concern due to excessive mortality, and grave socioeconomic consequences [1]. The symptoms can be ranged from mild, self-limiting respiratory tract infection to severe progressive pneumonia, which may lead to multiorgan failure and death [2]. The majority of the patients suffering from severe acute respiratory syndrome (SARS) usually require admission to the intensive care unit (ICU), and $>80 \%$ of patients admitted to ICU requiring invasive mechanical ventilation [3,4]. Approximately $20 \%$ of the hospitalized COVID-19 patients required ICU management [5]. Subsequently, critically ill patients are at significant risk of developing ventilator-associated pneumonia (VAP) [6,7].

The reasons may include breach of natural defences by invasive devices [8], sedation, and impairment of coughing and mucociliary clearance. The immunoparetic effects of critical illness $[9,10]$ widespread use of corticosteroids and empiric immunosuppressive medication, increased prevalence of co-morbid conditions [7], and the prolonged duration of artificial ventilation [4] may be the predisposing factors.

Deng et al. [11] indicated that bacterial pneumonia may be associated with mortality for patients with SARS-CoV-2 infection. Similarly, Wang et al. [12] reported almost four times higher levels of procalcitonin, a bacterial infection marker, among the deceased in comparison to the surviving COVID-19 patients. Another recent study also reported that COVID-19 associated with bacterial pneumonia was considerably more severe [13]. These findings indicate that VAP could worsen the clinical condition of COVID-19 patients. However, there is an important knowledge gap regarding the incidence, prevalence, and characteristics of secondary bacterial infection associated with SARS-CoV-2 
(Severe Acute Respiratory Syndrome Coronavirus2) requiring special attention by health professionals. Therefore, to treat COVID19 patients and the responsible use of antibiotics, it is crucial to identify the VAP associated with COVID-19, and the culprit pathogens associated with it.

We performed a systematic review of the studies and medical literature to identify the overall incidence of VAP, common organisms associated with, and outcome in COVID-19 patients in comparison to the patients with non-SARS-CoV-2 viral pneumonia.

\section{Methods}

This rapid systematic review was planned to identify the burden of VAP, common pathogen associated with, and outcomes in critically ill COVID-19 in comparison to patients with nonSARS-CoV-2 viral pneumonia. In view of the current public health emergency, our study was not registered for rapid decision-making.

\section{Search Methods and Data sources}

A comprehensive literature search on the major databases (PubMed Central, Medline, EMBASE, Ovid, and the Cochrane library), Google Scholar (https://scholar.google.com), and preprint platforms MedRxiv (https://www.medrxiv.org), from January 1st,2020 to May 31st, 2021 were performed with the following keywords: 'COVID-19' OR 'SARS-CoV-2'OR 'SARS' OR 'MERS' OR 'CORONA' AND 'VAP' OR 'Ventilator-Associated Pneumonia', as per the PRISMA statement [14].

Given the rapidly evolving nature of the literature on SARSCoV-2, bibliographies of relevant articles were also reviewed. Articles published in the English language, both prospective and retrospective, presenting clinical data for patients diagnosed with SARS-CoV-2 infection were included for full-text review. Randomized controlled trials, cohort studies, and case series were incorporated. The editorials, letters, and abstracts without full text and full articles except those in the English language were excluded (Figure 1).

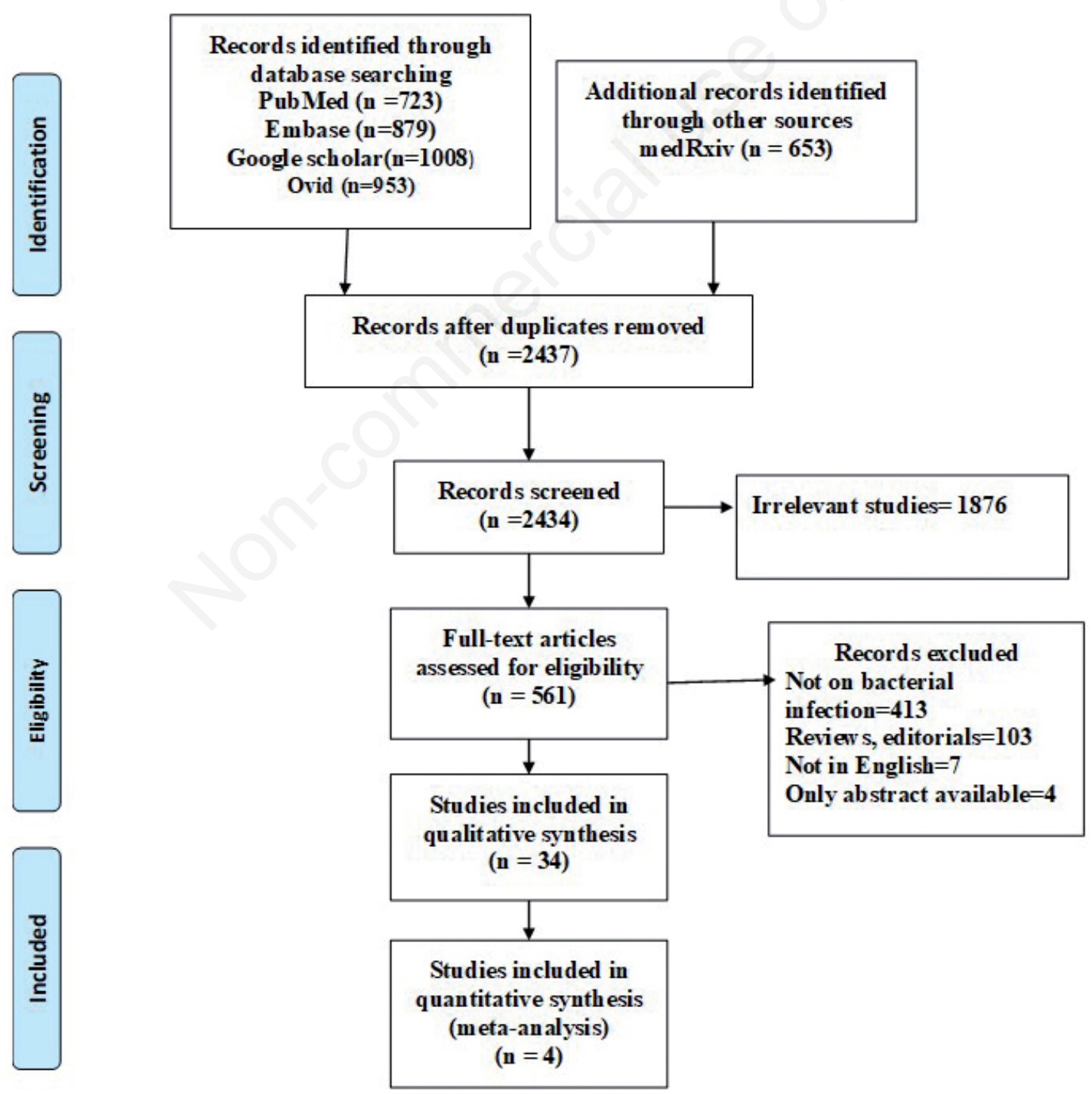

Figure 1. PRISMA 2009 flow diagram. 


\section{Study selection}

All titles and the abstracts were independently screened by two authors (SJ, SS) to determine whether all studies met the Inclusion criteria; then all full-text studies meeting the above criteria were then reviewed by two authors for final inclusion in the rapid systematic review. Disagreements that could not be resolved via consensus were then reviewed independently by an additional author (PK). The reference section of articles selected for inclusion was also searched to identify any additional studies for potential inclusion.

\section{Data extraction}

The data extraction was performed by two authors (SJ, SS) from the included studies using a spreadsheet, and cross-checked for accuracy and completeness. The following variables were extracted: study design (retrospective versus prospective), country/region of study, sample size, disease severity, associated comorbidities (i.e., chronic obstructive pulmonary disease, cardiovascular disease, hypertension), bacteriological testing methods, patients with acute respiratory co-infection, the proportion of patients with secondary bacterial infection, respiratory organisms identified and their proportions, and outcome.

\section{Data synthesis}

We (SS and PK) used Medcalc version 20 and Revman version 5 for conducting the frequentist meta-analysis. The Odds ratio (OR) with 95\% confidence intervals (CIs) was assessed as per the Cochrane Handbook for Systematic Reviews of Interventions [15]. Statistical heterogeneity was assessed with the $\mathrm{I}^{2}$ statistic, $>50 \%$ indicating substantial heterogeneity.

\section{Results}

\section{Basic characteristics}

Thirty-four (34) studies (seven prospective cohort studies and one case-control study) out of 4216 identified publications were included after satisfying the inclusion criteria (Figure 1; Table 1). Among the 32 COVID-19 related secondary bacterial infection studies, 23 (72\%) reports were from European countries, 6 (19\%) were from China, 3 (9\%) from the United States, and 28 studies addressed VAP in SARS-CoV-2 infection. Two non-COVID-19 studies were reported from Hong Kong and Qatar. Five articles were preprints.

\section{Outcome}

The overall prevalence of VAP was $48.15 \%$ (95\% CI 42.3\%$54 \%$ ) in 8901 mechanically ventilated COVID-19 patients (Supplementary Figure 1a). Among the 755 patients with other coronaviruses, SARS and MERS the prevalence of VAP was $24.17 \%$ (95\% CI 10.7\% to 40.8\%) (Supplementary Figure $1 \mathrm{~b}$ ).

The prevalence of mortality was $51.4 \%$ (95\% CI $42.5 \%-60 \%)$

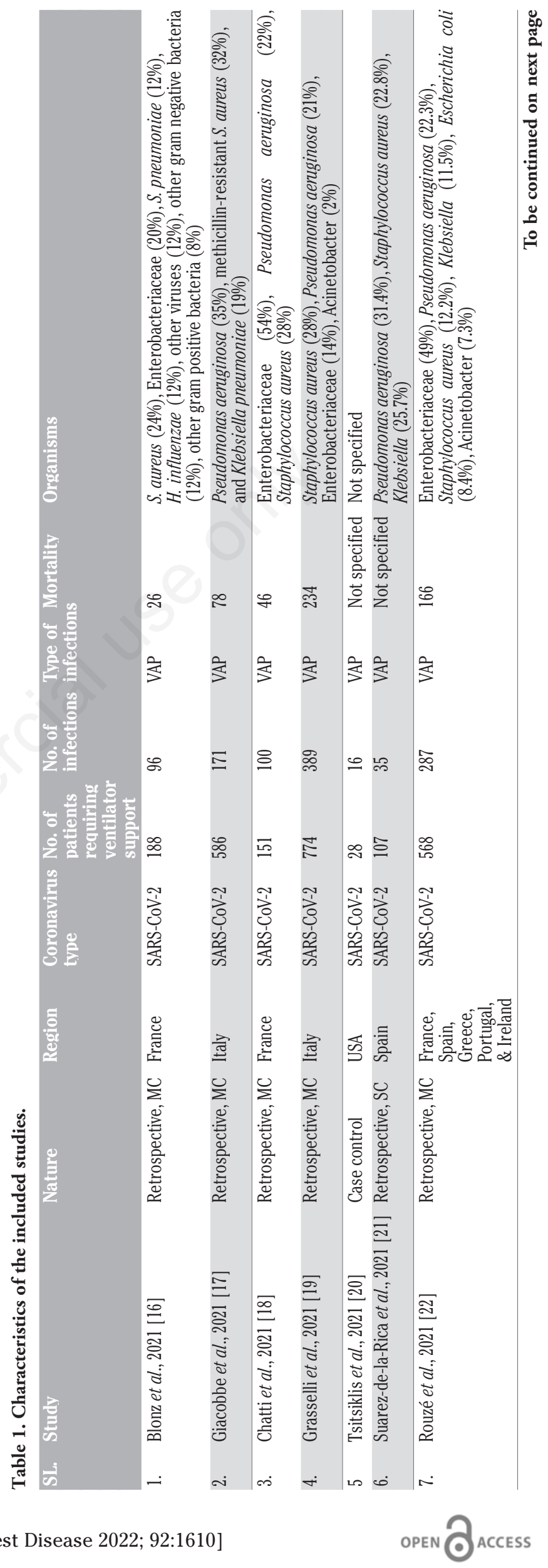




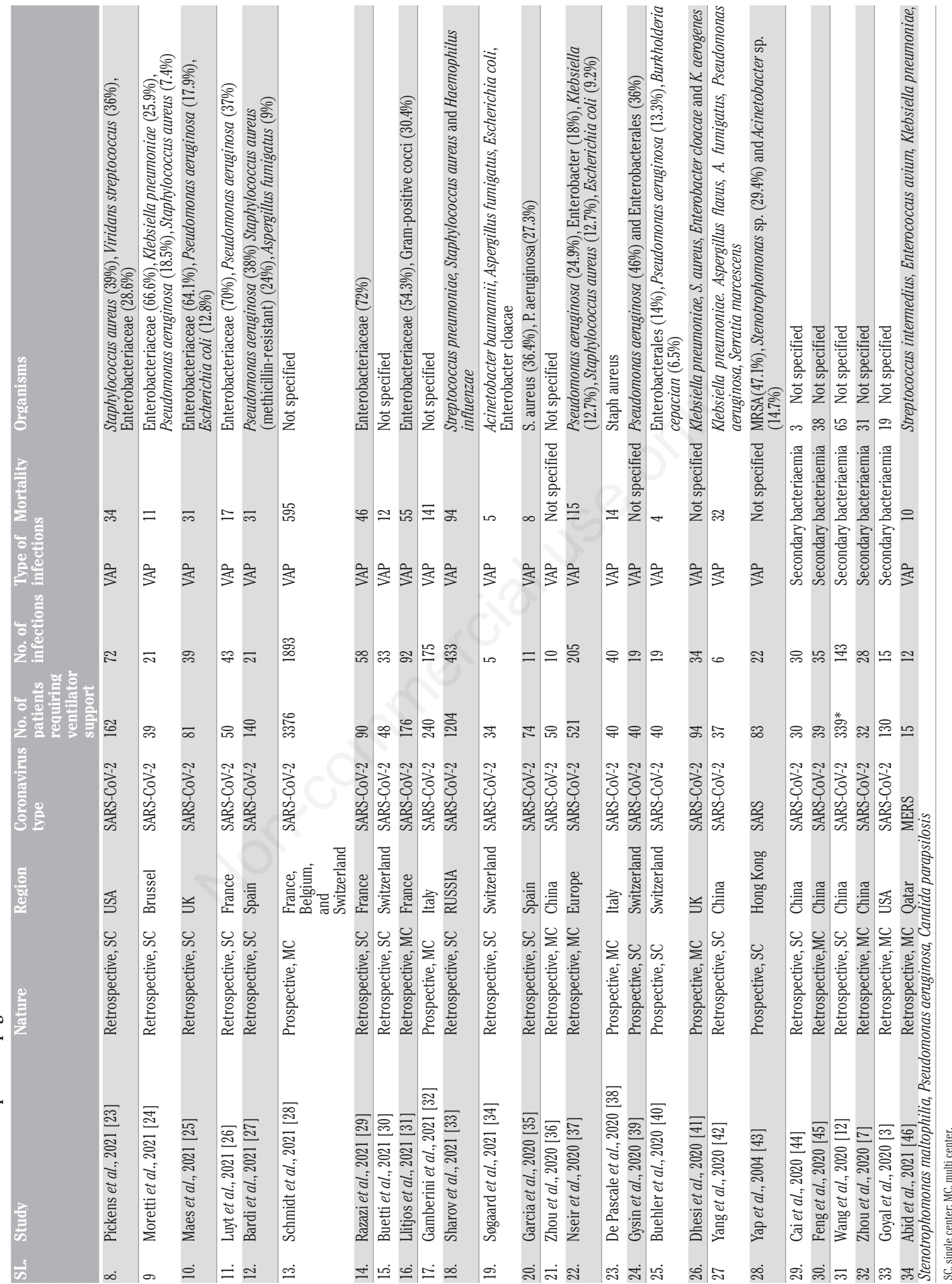


(Supplementary Figure 2a) among the COVID-19 patients and $33.7 \%$ (95\% CI $30.35 \%$ to $37.19 \%$ ) other non-COVID 19 patients with VAP (Supplementary Figure 2b).

\section{Meta-analysis}

\section{$V A P$}

The prevalence of VAP in COVID-19 patients in comparison to the other non-SARS-CoV-2 virus infected patients (nonCOVID-19) was evaluated in four articles with a total of 1541 patients. Significantly VAP was higher among the SARS-CoV-2 infected patients in comparison to patients with other non-COVID 19 patients. $\left(\mathrm{OR}=2.33 ; 95 \% \mathrm{CI} 1.75-3.11 ; \mathrm{I}^{2}=15 \%\right)$ (Figure $\left.2 \mathrm{a}\right)$.

\section{Mortality}

Mortality was assessed in 1541 patients. The COVID-19 patients had an increased risk of mortality in comparison to the other non-COVID 19 patients (OR=1.46; 95\%CI 1.15-1.86; $\mathrm{I}^{2}=0 \%$ ) (Figure $2 \mathrm{~b}$ ).

The most common pathogens involved in VAP are Gram-negative microorganisms- Escherichia coli, Klebsiella pneumoniae, Pseudomonas aeruginosa and Acinetobacter baumannii. Staphylococcus aureus is the main reported Gram-positive microorganism

\section{Publication bias}

The publication bias was assessed for the studies on VAP among COVID-19 patients. As per the Begg's test $(\mathrm{p}=0.69)$ and Egger's test $(\mathrm{p}=0.83)$ quantitively a publication bias is unlikely.

\section{Discussion}

We found that almost half of the critically ill COVID-19 patients developed VAP. Similarly, a recent systematic review also reported a higher incidence of bacterial co-infection in critically ill COVID-19 patients [47]. Another recent study also reported an increased occurrence of VAP in COVID-19 patients [48]. Though VAP is defined as pneumonia that occurs more than 48 hours following endotracheal intubation and invasive mechanical ventilation [49] a wide variation is noticed regarding the criteria for VAP, across the studies. The diagnosis can be challenging as a range of non-infectious diseases may mimic the clinical picture of radiographic infiltrates, systemic inflammation, and impaired oxygenation that typifies VAP [50]. Irrespective of definition, accurate diagnosis of VAP requires clinical signs of infection, microbiological documentation, and chest X-ray findings, which may be difficult to interpret due to pre-existing and overlapping parenchymal injury [51]. Based upon diagnostic criteria as per different settings the incidence of VAP may range between 5 to $40 \%$ [52] and represents approximately half of hospital-acquired pneumonia in patients on artificial invasive ventilation [53]. While many studies, failed to separate the reporting on critical and noncritical care settings, a large proportion of reported bacterial coinfections within coronavirus studies appear to be healthcare-associated, including central line-associated bloodstream infections, and ventilator-associated pneumonia $[12,44]$.

The COVID-19 patients frequently require prolonged invasive mechanical ventilation (MV) including prone ventilation, heavy sedation, and muscle blockers for several weeks which together with immunoparetic effects of critical illness, along with the exhausted medical resources in a pandemic scenario and crosscontamination accounts for a high risk of secondary hospitalacquired infections, primarily ventilator-associated pneumonia. VAP has already been reported as a complication in COVID-19hospitalized patients $[44,54]$. The SARS-CoV-2 is reported to cause immune dysregulation due to increased cytokine storm, leading to hyper-inflammation and defects in the lymphoid function $[55,56]$. This virus infects most of the ciliated cells in the alveoli, leading to progressive accumulation of debris and fluid in the

a

\begin{tabular}{|c|c|c|c|c|c|c|c|c|c|c|}
\hline \multirow[b]{2}{*}{ Study or Subgroup } & \multicolumn{2}{|c|}{ SARS-COV-2 } & \multicolumn{2}{|c|}{ Other VIRAL infection } & \multirow[b]{2}{*}{ Weight } & \multicolumn{2}{|l|}{ Odds Ratio } & \multirow{2}{*}{\multicolumn{2}{|c|}{$\begin{array}{c}\text { Odds Ratio } \\
\text { M-H, Random, } 95 \% \mathrm{Cl}\end{array}$}} & \\
\hline & Events & Total & Events & Total & & M-H, Random, $95 \% \mathrm{Cl}$ & & & & \\
\hline ROUZE et al,2021 & 205 & 568 & 107 & 482 & $59.8 \%$ & $1.98[1.50,2.60]$ & & & - & \\
\hline RAZAZI et al,2020 & 58 & 90 & 36 & 82 & $18.8 \%$ & $2.32[1.25,4.28]$ & & & $\longrightarrow$ & \\
\hline LUYT et al,2021 & 43 & 50 & 28 & 45 & $7.7 \%$ & $3.73[1.37,10.14]$ & & & & \\
\hline Llitjoset al,2021 & 92 & 176 & 11 & 48 & $13.7 \%$ & $3.68[1.77,7.68]$ & & & $\longrightarrow$ & \\
\hline Total $(95 \% \mathrm{Cl})$ & & 884 & & 657 & $100.0 \%$ & $2.33[1.75,3.11]$ & & & & \\
\hline Total events & 398 & & 182 & & & & & & & \\
\hline $\begin{array}{l}\text { Heterogeneity: } \mathrm{Tau}^{2} \\
\text { Test for overall effec }\end{array}$ & $\begin{array}{l}0.02 ; \mathrm{Ch} \\
\mathrm{z}=5.78\end{array}$ & $\begin{array}{l}=3.55 \\
<0.00\end{array}$ & $\begin{array}{l}d f=3(P=0 . \\
001)\end{array}$ & $=15 \%$ & & & 0.01 & ${ }_{\text {SARS-COV-2 }}^{1}$ & Other Viral & $\begin{array}{l}10 \\
10 \\
\text { pneumonia }\end{array}$ \\
\hline
\end{tabular}

b

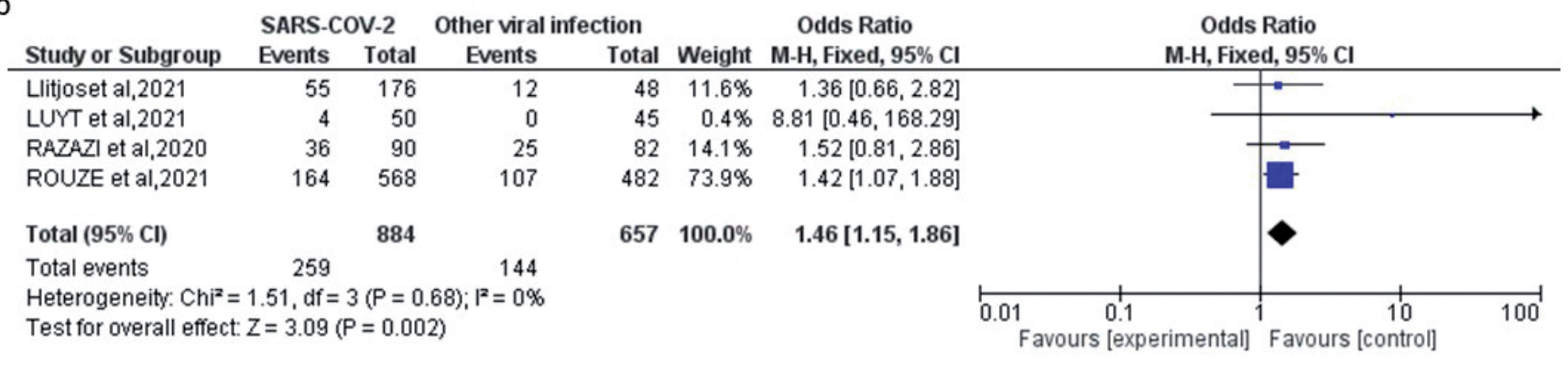

Figure 2. Impact of SARS-CoV-2 in critically ill patients. 
lungs, and consequently, acute respiratory distress syndrome (ARDS) develops [57].

The World Health Organization recommends oral instead of nasal intubation, the head-bed elevation of $30-45^{\circ}$, use of the closed suctioning system, periodically change of ventilator circuit, heat moisture exchanger every 5-7 days or when it is soiled or malfunctions to reduce the incidence of VAP in mechanically ventilated COVID-19 patients [58]. It is also important to remember that oral hygiene can decrease the risks of VAP [59]. All efforts are necessary to avoid VAP in COVID-19 patients. Secondary-infection has the potential to worsen the clinical condition and can increase the morbidity and mortality in these patients, as well as prolong and increase the costs of hospitalization. So early identification and the pathogens responsible for causing VAP is the key to successful treatment

In this manuscript, we aim to highlight the potential risk of ventilator-associated bacterial pneumonia in COVID-19 patients.

\section{Strengths and limitations}

We followed a robust literature search strategy with guidance from a healthcare information specialist and we used a dualreviewer process to screen and select appropriate studies meeting the inclusion criteria.

However, this systematic review had several limitations that must be considered. The bacterial infections may be under-or overrepresented, due to a lack of consistent bacteriological diagnostic and testing methods and a specific testing method. Furthermore, to differentiate bacterial colonization from VAP poses a challenge, especially in the context of COVID-19 infection. We only examined a subset of COVID-19 studies that reported the presence or absence of bacterial infections and the temporal relationship between bacterial and viral infection was not explicit; hence differentiating co-infection from secondary infection was challenging. This study included coronavirus infections from predominantly Europe, which may limit the generalizability of the findings and could impact the likelihood of bacterial secondary infection. Similarly, many studies failed to differentiate the healthcare setting and stage of COVID-19 infection where coinfection was identified. This makes differentiating community coinfection from nosocomial coinfection, such as hospital-acquired pneumonia or ventilator-associated pneumonia, in critical care difficult.

\section{Conclusions}

Critically ill COVID-19 patients are prone to develop VAP, which increases morbidity and mortality. Further studies regarding early identification of VAP and the culprit pathogens in COVID-19 patients to ensure antimicrobial stewardship for successful treatment are the need of the hour.

\section{References}

1. World Health Organization. Naming the coronavirus disease (COVID-19) and the virus that causes it. 2020. Accessed: Mar 29, 2020. Available from: https:/www.who.int/emergencies/diseases/novel-coronavirus-2019/technicalguidance/naming-the- coronavirus-disease-(covid-2019)-and-the-virus-that-causes-it

2. Zhu N, Zhang D, Wang W, et al. A novel coronavirus from patients with pneumonia in China, 2019. N Engl J Med 2020;382:727-33.

3. Goyal P, Choi JJ, Pinheiro LC, et al. Clinical characteristics of COVID-19 in New York City. N Engl J Med 2020;382:2372-4.

4. Grasselli G, Zangrillo A, Zanella A, et al. Baseline characteristics and outcomes of 1591 patients infected with SARS-CoV-2 admitted to ICUs of the Lombardy Region, Italy. JAMA 2020;323:1574-8.

5. Rodriguez-Morales AJ, Cardona-Ospina JA, GutiérrezOcampo E, et al. Clinical, laboratory and imaging features of COVID-19: A systematic review and meta-analysis. Travel Med Infect Dis 2020;34:101623.

6. incent J-L, Sakr Y, Singer M, et al. Prevalence and outcomes of infection among patients in intensive care units in 2017. JAMA 2020;323:1478-10.

7. Zhou F, Yu T, Du R, et al. Clinical course and risk factors for mortality of adult inpatients with COVI-19-19 in Wuhan, China: a retrospective cohort study. Lancet 2020;395:1054-62.

8. Álvarez-Lerma F, Palomar-Martínez M, Sánchez-García M, et al. Prevention of Ventilator-Associated Pneumonia. Critical Care Med 2018;46:181-8.

9. Morris AC, Datta D, Shankar-Hari M, et al. Cell-surface signatures of immune dysfunction risk-stratify critically ill patients: INFECT study. Intensive Care Med 2018;44:627-35.

10. Hotchkiss RS, Monneret G, Payen D. Sepsis-induced immunosuppression: from cellular dysfunctions to immunotherapy. Nat Rev Immunol 2013;13:862-74.

11. Deng Y, Liu W, Liu K, et al. Clinical characteristics of fatal and recovered cases of coronavirus disease 2019 in Wuhan, China: a retrospective study. Chin Med J (Engl) 2020;133:1261-7.

12. Wang L, He W, Yu X, H et al. Coronavirus disease 2019 in elderly patients: characteristics and prognostic factors based on 4week follow-up. J Infect 2020;80:639-45.

13. Dong X, Cao Y, Lu X, et al. Eleven faces of coronavirus disease 2019. Allergy 2020;75:1699-709.

14. PRISMA [Internet]. Preferred Reporting Items for Systematic reviews and Meta-Analyses extension for Scoping Reviews (PRISMA-ScR). Accessed: 18 April 2020. Available from: http://www.prisma-statement.org/

15. Cumpston M, Li T, Page MJ, et al. Updated guidance for trusted systematic reviews: a new edition of the Cochrane handbook for systematic reviews of interventions. Cochrane Database Syst Rev 2019;10:ED000142.

16. Blonz G, Kouatchet A, Chudeau N, et al. Epidemiology and microbiology of ventilator-associated pneumonia in COVID19 patients: a multicenter retrospective study in 188 patients in an un-inundated French region. Crit Care 2021;25:72.

17. Giacobbe DR, Battaglini D, Enrile EM, et al. Incidence and prognosis of ventilator-associated pneumonia in critically ill patients with COVID-19: A multicenter study. J Clin Med 2021;10:555.

18. Gragueb-Chatti I, Lopez A, Hamidi D, et al. Impact of dexamethasone on the incidence of ventilator-associated pneumonia and blood stream infections in COVID-19 patients requiring invasive mechanical ventilation: a multicenter retrospective study. Ann Intensive Care 2021;11:87.

19. Grasselli G, Scaravilli V, Mangioni D, et al. Hospital-acquired infections in critically ill patients with COVID-19. Chest 2021;160:454-65.

20. Tsitsiklis A, Zha B, Byrne A, et al. Impaired immune signaling and changes in the lung microbiome precede secondary bacte- 
rial pneumonia in COVID-19. medRxiv 2021;2021.03. 23.21253487.

21. Suarez-de-la-Rica A, Serrano P, De-la-Oliva R, et al. Secondary infections in mechanically ventilated patients with COVID-19: An overlooked matter? Rev Esp Quimioter 2021;34:330-6.

22. Rouzé A, Martin-Loeches I, Povoa P, et al. Relationship between SARS-CoV-2 infection and the incidence of ventilator-associated lower respiratory tract infections: a European multicenter cohort study. Intensive Care Med 2021;47:188-98.

23. Pickens CO, Gao CA, Cuttica M, et al. Bacterial superinfection pneumonia in SARS-CoV-2 respiratory failure. medRxiv 2021;2021.01.12.20248588.

24. Moretti M, Van Laethem J, Minini A, et al. Ventilator-associated bacterial pneumonia in coronavirus 2019 disease, a retrospective monocentric cohort study. J Infect Chemother 2021;27:826-33.

25. Maes M, Higginson E, Pereira-Dias J, et al. Ventilator-associated pneumonia in critically ill patients with COVID-19. Crit Care 2021;25:25. Erratum in Crit Care 2021;25:130.

26. Luyt CE, Sahnoun T, Gautier M, et al. Ventilator-associated pneumonia in patients with SARS-CoV-2-associated acute respiratory distress syndrome requiring ECMO: a retrospective cohort study. Ann Intensive Care 2020;10:158.

27. Bardi T, Pintado V, Gomez-Rojo M, et al. Nosocomial infections associated to COVID-19 in the intensive care unit: clinical characteristics and outcome. Eur J Clin Microbiol Infect Dis 2021;40:495-502.

28. COVID-ICU Group on behalf of the REVA Network and the COVID-ICU Investigators. Clinical characteristics and day-90 outcomes of 4244 critically ill adults with COVID-19: a prospective cohort study. Intensive Care Med 2021;47:60-73.

29. Razazi K, Arrestier R, Haudebourg AF, et al. Risks of ventilatorassociated pneumonia and invasive pulmonary aspergillosis in patients with viral acute respiratory distress syndrome related or not to Coronavirus 19 disease. Crit Care 2020;24:699.

30. Buetti N, Mazzuchelli T, Lo Priore E, et al. Early administered antibiotics do not impact mortality in critically ill patients with COVID-19. J Infect 2020;81:e148-9.

31. Llitjos JF, Bredin S, Lascarrou JB, et al. Increased susceptibility to intensive care unit-acquired pneumonia in severe COVID-19 patients: a multicentre retrospective cohort study. Ann Intensive Care 2021;11:20.

32. Gamberini L, Tonetti T, Spadaro S, et al. Factors influencing liberation from mechanical ventilation in coronavirus disease 2019: multicenter observational study in fifteen Italian ICUs. J Intensive Care 2020;8:80.

33. Sharov KS. SARS-CoV-2-related pneumonia cases in pneumonia picture in Russia in March-May 2020: Secondary bacterial pneumonia and viral co-infections. J Glob Health 2020;10:020504.

34. Søgaard KK, Baettig V, Osthoff M, et al. Community-acquired and hospital-acquired respiratory tract infection and bloodstream infection in patients hospitalized with COVID-19 pneumonia. J Intensive Care 2021;9:10.

35. Garcia-Vidal C, Sanjuan G, Moreno-García E, et al. Incidence of co-infections and superinfections in hospitalized patients with COVID-19: a retrospective cohort study. Clin Microbiol Infect 2021;27:83-8.

36. Zhou F, Yu T, Du R, et al. Clinical course and risk factors for mortality of adult inpatients with COVID-19 in Wuhan, China: a retrospective cohort study. Lancet 2020;395:1054-1062. Erratum in: Lancet 2020;395:1038.
37. Nseir S, Martin-Loeches I, Povoa P, et al. Relationship between ventilator-associated pneumonia and mortality in COVID-19 patients: a planned ancillary analysis of the coVAPid cohort. Crit Care 2021;25:177.

38. De Pascale G, De Maio F, Carelli S, et al. Staphylococcus aureus ventilator-associated pneumonia in patients with COVID-19: clinical features and potential inference with lung dysbiosis. Crit Care 2021;25:197.

39. Gysin M, Acevedo CT, Haldimann K, et al. Antimicrobial susceptibility patterns of respiratory Gram-negative bacterial isolates from COVID-19 patients in Switzerland. medRxiv 2021:2021.03.10.21253079.

40. Buehler PK, Zinkernagel AS, Hofmaenner DA, et al. Bacterial pulmonary superinfections are associated with unfavourable outcomes in critically ill COVID-19 patients. medRxiv 2020:2020.09.10.20191882.

41. Dhesi Z, Enne VI, Brealey D, et al. Organisms causing secondary pneumonias in COVID-19 patients at 5 UK ICUs as detected with the FilmArray test. medRxiv 2020:2020.06.22. 20131573.

42. Yang X, Yu Y, Xu J, et al. Clinical course and outcomes of critically ill patients with SARS-CoV-2 pneumonia in Wuhan, China: a single-centered, retrospective, observational study. Lancet Respir Med 2020;8:475-81. Erratum in: Lancet Respir Med 2020;8:e26.

43. Yap FH, Gomersall CD, Fung KS, et al. Increase in methicillin-resistant Staphylococcus aureus acquisition rate and change in pathogen pattern associated with an outbreak of severe acute respiratory syndrome. Clin Infect Dis 2004;39:511-6.

44. Cai Q, Huang D, Ou P, et al. COVID-19 in a designated infectious diseases hospital outside Hubei Province, China. Allergy 2020;75:1742-52.

45. Feng Y, Ling Y, Bai T, et al. COVID-19 with different severities: A multicenter study of clinical features. Am J Respir Crit Care Med 2020;201:1380-8.

46. Ben Abid F, El-Maki N, Alsoub H, et al. Middle East respiratory syndrome coronavirus infection profile in Qatar: An 8year experience. IDCases 2021;24:e01161.

47. Lansbury L, Lim B, Baskaran V, Lim WS. Co-infections in people with COVID-19: a systematic review and meta-analysis. J Infect 2020;81:266-75.

48. Ippolito M, Misseri G, Catalisano G, et al. Ventilator-associated pneumonia in patients with COVID-19: A systematic review and meta-analysis. Antibiotics (Basel) 2021;10:545.

49. Plachouras D, Lepape A, Suetens C. ECDC definitions and methods for the surveillance of healthcare-associated infections in intensive care units. Intensive Care Med 2018;44: 2216-8.

50. Meduri GU, Maul din GL, Wunderink RG, et al. Causes of fever and pulmonary densities in 337 patients with clinical manifestations of ventilator-associated pneumonia. Chest 1994;106:221-35.

51. Chastre J, Luyt CE. Does this patient have VAP? Intensive Care Med 2016;42:1159-63.

52. Papazian L, Klompas M, Luyt CE. Ventilator-associated pneumonia in adults: a narrative review. Intensive Care Med 2020;46:888-906.

53. Kózka M, Sega A, Wojnar-Gruszka K, et al. Risk factors of pneumonia associated with mechanical ventilation. Int $\mathrm{J}$ Environ Res Public Health 2020;17:656.

54. Wu J, Liu J, Zhao X, et al. Clinical Characteristics of imported cases of coronavirus disease 2019 (COVID-19) in Jiangsu 
Province: A multicenter descriptive study. Clin Infect Dis 2020;71:706-12.

55. Giamarellos-Bourboulis EJ, Netea MG, Rovina N, et al. Complex immune dysregulation in COVID-19 patients with severe respiratory failure. Cell Host Microbe 2020;27:9921000.e3.

56. Zhou Z, Ren L, Zhang L, et al. Heightened innate immune responses in the respiratory tract of COVID-19 patients. Cell Host Microbe 2020;27:883-90.e2.

57. Perico L, Benigni A, Remuzzi G. Should COVID-19 concern nephrologists? Why and to What extent? The emerging impasse of angiotensin blockade. Nephron 2020;23:19.

58. World Health Organization. Clinical management of severe acute respiratory infection (SARI) when COVID-19 disease is suspected: interim guidance. 13 March 2020. Accessed: Mar 29, 2020. Available from: https://apps.who.int/iris/handle/ $10665 / 331446$

59. Hua F, Xie H, Worthington HV, et al. Oral hygiene care for critically ill patients to prevent ventilator-associated pneumonia. Cochrane Database Syst Rev 2016;25:CD008367. 